\title{
Desarrollo, integración y dependencia en Centroamérica
}

\begin{abstract}
Edelaekto Torres-Rivas, abogado y sociólogo (Flacso) guatemaltcco. Actualmente cs miembro del Instituto Latinoamericano de Planificación Económica y Social (ILPes). Es autor de varios trabajos de su especialidad; vgr. Las clases sociales en Gualemala (1962); Posibilidades y modalidades del desarrollo en Centroamérioa (1967); Incorporación de la juventud al mercado de trabajo
\end{abstract}

(1969).

El clima eufórico de la segunda postguerra abrió para las sociedades centroamericanas la posibilidad de superar el modelo de desarrolio económico y social que desde mediados el siglo xix veria funcionando y que en el momento de su constitución facilitó el cumplimiento de dos finalidades básicas: el establecimiento de lazos económicos con el cxterior y la consolidación de una estructura politica interna, de fachada liberal pero de contenido social oligárquico que aún perdura. En efecto, con la producción cafetalera Centroamérica se constituye como una sociedad agroexportadora, con la excepción de Honduras donde la mineria primero y el banano después fueron las principales actividades.

El análisis de los problemas del desarrolio en la sociedad centroamericana permite establecer lineas de conocimiento que, por una parte, son comunes para el resto de América Latina, y' por la otra, ejemplifican con rasgos específicos las modalidades que el cambio social y ecónómico adquiere en esta región periférica. Las repúblicas centroamericanas llegan a la década del treinta como apéndices agrarios de las economías centrales. La crisis mundial de aquella recha señala el inicio de la crisis de todas las estructuras nacionales ligadas al café, y en general, a la economia de exportación. Asi, quedaron al desnudo fuerzas y rasgos de persistente vigencia histórica que, por su magnitud y duración subrayaban la falta de viabilidad del sistema agroexportador. Las caracteristicas más sobresalientes del comportamiento del sistema a partir de 1930 hasta fines de la postgucrra fucron el estancamiento económico y la dicladura politica; 
ESTUDIOS I X T E R N ACIO X A L E S

ésta surge como una necesidad que expresa las limitadas posibilidades democrático-liberales de la oligarquía nacional.

A partir de 1945 se inicia la crisis propiamente politica de la llamada república liberal, no tanto porque comiencen a insinuarse nuevas formas o vias para el crecimiento económico sino debido a que se intenta modificar el orden político anterior basado en formas autoritarias y exclusivistas de gobierno. Lo primero tiene relación con los intentos de industrialización, que desde la década del cincuenta, se ha convertido en sinónimo de desarrolio, y lo segundo alude a la aparición de nuevos grupos sociales en la estructura politica, especialmente las capas medias urbanas, que manipulando el descontento popular acumulado en los largos años de estancamiento, presionaron por una apertura del sistema $y$ ' para asegurarse nuevas formas de participación social.

Este trabajo presenta sumariamente el análisis del último periodo (1944-54) que desemboca en el proyecto de integración económica centroamericana y que se presenta como la alternativa favorable para constituir un nuevo marco económico c institucional dentro del cual se espera dinamizar la sociedad total. Los hechos económicos más significativos son, para este lapso de tiempo, el surgimiento de nuevos productos de cxportación (algodón, carne y' azúcar) que no implican una alteración sustancial en lá estructura del comercio extcrior; la declinación del enclave bananero y la modificación de las condiciones en que opera en la plantación extranjera; la aparición del capital norteamericano en la naciente industria manufacturera y finalmente, un vigoroso impulso en el comercio intercentroamcricano, que removió la capacidad ociosa de la industria tradicional, pero que no ha correspondido a una política regional de industrialización autónoma.

Durante estos veinte años se introdujeron en el sistema politico modificaciones de diversa significación histórica entre los grupos sociales dominantes, siendo lo más importante cl desequilibrio de la hegemonia oligárquico-terrateniente $y$ cl aparecimiento de grupos de interćs social ligados a la industria, las finanzas $y$ a otras actividades productivas nuevas. En los primeros años de la postguerra surgieron en casi todos lós paises de la región movimientos populistas encabezados por lideres y orientados ideológicamente por la clase media. Dichos movimicntos facilitaron la liquidación de los gobiernos militares surgidos en la época de la crisis mundial del $3^{n}$, intentaron modernizar la estructura del Es- 
Edelberto Torres-Rivas / Desarrollo, integración y dependencía en Centroamérica tado y' establecer un sistema institucional de partidos $y$ organizaciones obreras. Dentro de esta categoria de "populismo" centroamericano se incluyen movimientos $y$ gobiernos tan diversos como los que encabezaron Arévalo y Arbenz en Guatemala, Figueres en Costa Rica y Villeda Morales en Hondurás y en alguna medida, Osorio, en El Salvador. Sin embargo, el desequilibrio institucional y la crisis social pasan a constituir sintonas crónicos del debilitado sistema politico; con la importante excepción de Costa Rica, los sectores sociales dominantes - donde continúa influyendo poderosamente la oligarquia cafetalera- han intentado resolver a través de formas militar-autoritarias las causas de la crisis politica y las ambigüedades y limitaciones del proceso de cambio; en los últimos años se ha acentuado la tendencia a poner fuera de la legalicład las luchas sociales $y$ a excluir de la participación politica a importantes sectores, negándose de esta manera el ideario reformista que en la postguerra defendieron los movimientos populares y los idcólogos de la clase media. De ahi que la violencia surja en más de algún pais centroamericano como una forma anormal de participación politica.

En relación con las posibilidades reales de desarrollo de la sociedad centroamericana, el hecho más sobresalientc lo constituye el proyecto de constitución de un mercado común, como etapa culminante de una política integracionista que se configura como un esfuerzo persistente por alcanzar niveles más altos de crecimiento económico en el conjunto de una situación donde el "modelo" agrario-exportador no podia ya asegurar condiciones favorables al desarrollo.

Originalmente el camino de la integración económica fue concebido como un proyecto general de cambio social a través del cual era posible alcanzar el doble propósito de reconstituir la unidad centroamericana, rota en la década del cuarenta del siglo $\mathrm{xIx}$ (cuando se disolvió la república Federal de Centroamérica); y asegurar condiciones de mayor autonomía e independencia $y^{\prime}$ disminuir asi los tradicionales vinculos de dependencia establecidos con el mercado capitalista mundial, a mediados del siglo pasado. De tal suerte que la integración económica fue presentada de manera programática como sinónimo de desarrollo e independencia nacional. Sin embargo, el carácter de las fuerzas sociales que actualmente dinamizan el proceso y el marco histórico en que tal esfuerzo se desenvuelve, imponen limites y restan potencialidad a lo que se considera el camino viable para el desarrollo de esta región. 
Los esfuerzos de carácter politico-militar para alcanzar la unidad centroamericana dominaron hasta la década del $4^{0}$ de este siglo y jalonaron una reitcrada cadena de fracasos, que probablemente pesaron en el ánimo de los actuales responsables de las decisiones públicas. Por ello la reconstitución juridico-política de la vieja República Fcderal se ha dejado como objetivo a largo plazo para impulsar en cambio medidas pragmáticas de conveniencia económica. No es posible hacer en este trabajo el recuento de aquellos esfuerzos y de estas medidas; basta mencionar que en la postguerra se difundió rápidamente una ideología -difusamente expresada- de contenido nacional-desarrollista que suponia, por una parte, que la situación de subdesarrollo es solamentc una etapa en el camino hacia la sociedad industrial de tipo europeo o norteamericano $y$, por la otra, que la industrialización podría resolver todos los problemas sociales y económicos heredados del desarrollo inducido desde afuera; la realidad evoluciona, sin embargo, en otra dirección.

Tal era el clima cuando en r95 la CEPAL aprobó a solicitud de los gobicrnos centroamericanos la resolución 9-IV que constituye el fundamento del Programa de Integración Económica'. Hasta 1957 transcurrió una etapa de estudios y de logros preliminares en el campo institucional, a través de la suscripción de numcrosos tratados bilaterales que condujeron en $195^{8}$ a la necesidad de utilizar instrumentos multinacionales. En junio de ese año se suscribió el Tratado Multilateral de Libre Comercio e Integración, que liberó los productos originarios, conforme una lista anexa y señaló un periodo de 10 años para alcanzar la Zona de Libre Comercio. La culminación juridico-institucional de este proceso se alcanzó con la firma del Tratado General de Integración Económica Centroamericana (Managua, Nicaragua, diciembre de 1960 ), con la excepción de Costa Rica que no adhirió hasta 1962 . Con este documento,

${ }^{2}$ Esta resolución, aprobada en el $4^{\circ}$ Periodo de Sesiones de cepar, cstableció el Comité de Cooperación Económica, formado por los winistros de Economia de ha región; los objetivos iniciales eran modestos: "desarrollar la producción agrícola e incustrial y los sistcmas de transporte en forma que pronueva la integración de sus ecomomias y la formación de mercados más amplios, mediante el intercambio de sus productos, la coordinación de sus planes de fomento y la creación de empresas en que todos o algunos de tales paises tengan interés". 
Edelberto Torres-Rivas / Desarrollo, integración y dependencial cu Centroamérica el libre comercio pasó a ser la regla general al otorgar libre tránsito a todos los producios naturales y manufacturados -originarios de Ins socicdades participantes, con excepciones especificas. El Tratado creó además los organismos corrcspondientes: cl Consejo Económico, de máximo nivel decisorio; el Conscjo Ejecutivo, de nivel técnico y la Sccretaria Permanente ( $\operatorname{sic} x$ ) encargada de coordinar $y$ dirigir la práctica de la aplicación de los tratados, convenios y disposiciones vigentes. Junto a estos instrumentos juridicos $y$ administrativos han sido creadas otras instituciones complementarias tales como el Banco Centroamericano de Integración Económica, el Instituto Centroamericano de Investigación y Tecnologia Industrial, la Escucla Superior de Administración Pública, el Consejo Nonctario y muchos dotros de especialización sectorial.

\section{DINÁMICA SOCIAL DE LA INTEGRACIÓN ECONÓMICA}

Por sus características, el proyecto desarrollista contenido en el mercado común busca movilizar nucvas fuerzas sociales que están interesados \% sc apoyan sobre la promoción de un mercado nacional capaz de ascgurar continuidad $y$ dinamismo al sistema económico. Pero ninguna reorientación de politica económica hubiera sido posible sin que previamente se hubiese alterado en alguna medida el sistema de dominación cstablecido y cambiaran cicrtos rasgos tradicionales del Estado liberal. Los años que siguicron a la postguerra, permitieron en Centroamérica alguna modificación de la base social de la dominación política tradicional, aunque en última instancia sólo se trate de una ampliación relativa, defacto, de la coalición oligárquica, en virtud de la cual el peso específico de los grupos agrario y comercial-cxportadores es proporcional $y$ relativamente menos decisivo.

Apoyados en general sobre la coy'untura favorable del comercio cxierior, se posibilitaron algunos cambios sociales significativos, tales como el surgimiento politico de grupos de clase media urbana y la organización gremia! de nuevos sectores de interés social, el incremen:o de la cducación popular, tendencias crecientes de la urbanización (cspecialmente de las ciudades capitales), ampliación de las funciones del Estado acompañadas de una relativa modernización de la administración públi- 


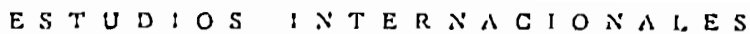

cá y una expansión del sector terciario. Lá hipótesis que se intenta formular, por lo tanto, es que el proyecto de mercado común $y$, en general, la politica integracionista, responde a una nueva visión $y$ a actitudes modernas de los grupos sociales que emergen más acusadamente en la décadal del cincuenta, en especial los ligados al sector comercial-financiero c industrial, que ahorá comparten en la región el liderazgo $y$ la dirccción politica de! Estado junto a la burguesia agrario-exportadora; en este arreglo circunstancial, por lo demás no siempre estable, se han ajustado a la estructura estatal importantes grupos de clase media que, renunciando a sus anteriores objetivos radicales, aportan alguna potencialidad renovadora a la estructura de la sociedad en transición.

A partir de 1945 comenzaron a manifestarse en el panorama político en Costa Rica, El Salvador y Guatemala nucvas fuerzas sociales que pugnaban por un cambio sustancial en las relaciones internas de dominación $y$ en las establecidas con el mercado internacional. La critica antioligárquica fue una constante de tales movimientos politicos y era obvio que los terratenientes cafetaleros no podian ser ya los protagonistas de la nuevá situación de mercado quc se buscó establecer, ya que como clase no podian tener interés en una politica de desarrollo donde adquirian mayor importancia las actividades urbano-industriales. Las presiones a favor de la industrialización aparecen, por eso, como objetivo polílico policlasista en el centro del cual se busca hacer del Estado el responsable $y$ ejecutor del proyecto, y' no como reivindicación histórica de una determinada clase social. Es clccir, no coinciden la demanda por la industrialización con una dinámica de algún sector empresarial emergente y en conflicto con los resabios "feudales" de la economía.

De ahi que se considere que toda la politica económica que apunta hacia el fortalecimiento del mercado interior, la diversificación económica nacional $y$ la industrialización, y más aún, hacia la planificación y el control estatal expresan una situación de poder distinta; aquella politica cconómica, en efecto, tiene como condición la posibilidad de un nuevo lipo de alianza o de arreglo politico en cl que ya no sólo predominan los intereses tradicionales de la oligarquia. Esa apertura se alcanzó de manera precaria cn la región y fue mediatizada por las relaciones de dependencia que se refuerzan en los últimos años. De ahi que sea pertincnte preguntarse si puede haber industrialización sin cambios profun- 
Edelberto Torres-Rivas / Desarrollo, integración y dependencia en Centroamérica dos en la estructura agraria, como también conocer las modalidades que adopta este proceso, impulsado desde el Estado por diversos grupos sociales divergentes y $\sin$ la presencia de un sólido grupo empresarial privado.

Después de casi una década de esfuerzos por la industrialización sustitutiva en el marco de la politica de integración, es posible empezar a conocer algunas de esas modalidades, asi como las limitaciones que actualmente el crecimiento económico enfrenta. Por otro lado, en el nivel politico ha quedado establecido que la crisis de las formas tradicionales de dominación sólo ha servido para probar la extraordinaria vitalidad histórica de los grupos ligados a la actividad agroexportadora $y$, a la inversa, que la emergencia de nuevas fuerzas sociales en el juego politico no significan que esos grupos tradicionales hayan aceptado las condiciones de modificación de sus propias bases de prestigio social y de poder económico.

Por el contrario, una de las condiciones de la eventual alteración del slatu quo que supone la integración económica, es el mantenimiento de la vicja estructura agraria a costa de la gran masa campesina. En otras palabras, el crecimiento económico concebido como industrialización deja de lado, sin modificación a largo plazo, las relaciones suciales semipatrimoniales establecidas con la peonada campesina y las mantiene, contradictoriamente, en parte marginadas de la economia monetaria Es esta una de las contradicciones insalvables de la mecánica integracionista, en la medida que se convierte sólo en integración del pequeño y naciente sector moderno de los sistemas nacionales, a costa del resto del mismo y en especial de los grupos sociales más necesilados de mejorar su participación en el ingreso y en el consumo, o de recibir ventajas sociales y politicas por largo tiempo pospuestas.

Probablemente sea el aspecto social el más importante de toda la politica desarrollista contenida en el programa de la integración aplicado en la última década. ¿En beneficio de quién se realiza la integración económica? ¿Cuáles son las fucrzas sociales que la dinamizan y bajo qué condiciones? Es bien conocido el problema de las opciones sociales y la diferente manera como se reparten los frutos yr las cargas que el desarrollo económico implica; no cabe clida que los grupos o clases sociales de la sociedad centroamericana obtienen dividendos distin- 
ESTUDIOS INTERNACIONALE S

tos, casi en relación inversa a su contribución real, ya que los mecanismos existentes en la estructura política asi lo establecen de manera absolutamente consciente $y$ "natural".

Las condiciones sociales y politicas actuales favorecen exclusivamente a un sector social; los grupos propietarios en general $y$, más especificamente, los sectores industrial-comercial-financieros de origen nacional y' extranjero; excluyen, casi sin concesiones, a la clase obrera y a los extendidos sectores populares. El sector asalariado ni siquiera ha recibido beneficios indirectos tales como una ampliación de la seguridad social o una eficaz implementación de la législación laboral y de la protección social; algunos grupos medios urbanos se satisfacen hasta ahora con su participación como grupo técnicoburocrático en la relativa expansión del sector privado y público o aportando su cuestionable capacidad de consumo.

Las ventajas y los costos sociales así determinados obedecen a una inspiración claramente oligárquica en el estilo de la dominación política $y$ a una voluntad conscientemente expresada de hacer pagar el precio del desarrollo a los sectores sociales que, probablemente, son los únicos que podrian dinamizar el proceso de crecimiento.

De esto se deriva otra limitación importante para el desarrollo social centroamericano. La única posibilidad de aprovechar las ventajas sociales de la creación de un mercado común radica en una efectiva reordenación de los intereses y fuerzas de la sociedad civil que cl Estado pretende representar, seguida de una modificación de toda la dinámica económica y social que conduzca a redistribuir equitativamente los costos y las ventajas del crecimiento. Las medidas reformistas aplicadas hasta sus últimas consecuencias, que en, su momento reivindicaron los grupos populares y de clase media en la década del cuarenta, habrian facilitado aquella dinámica, tales como la reforma agraria burguesa, la diversificación del-comercio exterior, el fortalecimiento del sector público y la formación de un Estado empresario, asi como la creación de condiciones para la organización y participación de los sectores asalariados en la defensa de su ingreso.

Algunos análisis sobre este particular señalan que la integración en Centroamérica es tipicamente una promoción de empresarios, más influida por los hombres de negocios que por los políticos. No calbe 

duda que en última instancia la integración económica ha sido proyectada como desarrollo industria!, no importe que el mismo se desenvuelva como un crecimiento regionalmente equilibrado o no. Hasta el presente, los paises más beneficiados en tèrninos de los montos de transacciones mercantiles efectuadas son El Salvador y Guatcmala (casi el $70 \%$ del total) $y^{\prime}$ en menor medida Costa Rica. Internamente, como la dinámica del proceso se redujo al perfeccionamiento de una zona de libre comercio (aunque el objeto de una unión aduanera fue proyectado para un plazo de 10 años que se cumplió en ig68), la tendencia que sigue el reparto de los beneficios favorece al grupo comcrcialindustrial, donde el peso de los intereses norteamericanos es crecientemente decisivo.

Es notoria la participación del capital extranjero en la manufactura nacional, que aprovecha las facilidades abiertas con la ampliación de los mercados nacionales y las medidas de estimulo fiscal y protección arancelaria. Quien estaba mejor preparado para aprovcchar tal coyuntura era el sector extranjero de! mercado, en la medida que las necesidades de capital y los requerinientos tecnológicos, la expcriencia empresarial $y$ hasta ciertas materias primas $y / 0$ productos semielaborados exigidos por las condiciones actuales de la industrialización, se localizan o vienen del exterior. Los inversionisias norteamericanos, por ejemplo, se han hecho cargo de casi todos los nuevos renglones fabriles (fertitizantes, refinerias de petróleo, neumáticos y câmaras de automóvil, insecticidas $y$ pinturas, bulbos eléctricos, vidrio $y$ otros) $y$ se han asociado a empresarios nacionales en algunos otros rubros. En otros casos hay una desnacionalización real en renglones tradicionaies de la manufactura local, como la industria texti! de larga existencia en la región. La asociación con el capital extranjero parece ser el precio que debe pagar el empresario nacional para poder ampliar y modernizar sus instalaciones fabriles. .

Por otro lado, las relacioncs entre los grupos cconómicos nacionales dominantes se modifican lentamente, sin que aparezcan aún los conflictos verticales, es decir, el enfrentamiento entrc sectores económicos, por cjemplo como el que podria suponerse entre terratenicntes tradicionales e industriales innovadnres. Posiblemente esta ausencia -aparente- de conflicto se deba al origen social oligárqui- 


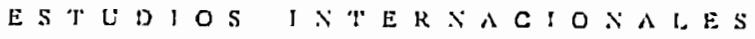

co de estos últimos $y / 0$ a la procedencia de sus capitales de inversión; el enfrentamiento hasta ahora es más cuidente en la dimensión horizonlal, que se expresa en forma de pugnas "nacionalistas", como ia que han protagonizado los gobiernos de Honduras y Nicaragua en defensa de sus cmpresarios privados para asegurarse un trato preferencial. Este juego de fuerzás deberá conducir, tarde o temprano, a la cristalización de una interdependencia múltiple al nivel del nuevo espacio cconómico, con la consiguiente redistribución del poder social en el área. Por otro lado, la integración entre sucicdades subdesarrolladas, es decir, que realizan una función históricamente determinada en el seno del mercado capitalista mundial, adquiere los rasgos de una asociación virtual entre la burguesia de la zona periférica $y^{\prime}$ la de la economia metropolitana. Las posibles contradicciones entre ambos grupos, nacional e internacional, apenas podrian expresar la debilidad de la burguesia local y las limitaciones de su bargaiming, asi como las modalidades de la dependencia resultante, que se analizan en la parte final de este trabajo.

El clima favorable creado en torno suyo por el libre comercio intercentroamericano (que saltó de los 8,6 millones de dólares en t950 a 213,5 millones en ig67) sumado a los mencionados incentivos fiscales, arancelarios y' de otro tipo, ha sido aprovechado casi sólo por los grupos empresariales para remover capacidad ociosa instalada en sus $\mathrm{cm}$ presas, $y$ por los comerciantes, intermediarios en el libre tránsito de mercaderias. Ha habido un desplazamicnto de capitales de la agricultura a la industria y el comercio, especialmente en El Salvador y Costa Rica, a medida que la rentabilidad de la inversión industrial empieza a ser más alta que la que rinden los cultivos tradicionales. La politica integracionista, al vincular más o menos rápidamente al pequeño sector moderno de cada uno de los sistemas nacionales en el espacio económico mayor, podria consoliclar una burgucsia regional, politicamente dominante, aliada y penctrada por ei capital eximanjero; la dirección en que se encaminan las inversiones de cstos tiltimos, permite postular tal tendencia. Sin embargo, un localismo gaIopante emerge como factor dirruptivo importante; se trata de un "nacionalismo" defensivo donde has tanto orgullo politico local cono falta de visión histórica y que determina los aludidos conflictos entre la misma clase capitalista pero disfrazados de enfrentamientos 
Edelberto Torres-Rivas / Desarrollo, integración y dependencia en Centroamérica nacionales. Es sabido que la tendencia integracionista no excluye sino implica la cooperación antagónica en el mercado; sin embargo, las zonas de conflicto, que tienen su origen real en la formación relativamente desigual de los sistemas económicos nacionales, limitan la concentración de los esfuerzos y la consolidación del proceso de "centroamericanización" de tales grupos económicos.

En esta situación sobresale el empuje renovador del sector privado de El Salvador, quizás el núcleo mejor preparado para la tarea industrial; Honduras y Nicaragua, que no llegaron a tener una agricultura estable de exportación en cl pasado, se han resentido largo tiempo por la falta de grupos económicos que encabccen con éxito y cxperiencia la diversificación requerida. En Honduras, el liderazgo económico correspondió siempre al empresario extranjero y el enclave agricola (bananero) ha dificultado hasta la misma integración fisica de su territorio. En opinión de quienes han tratado de describir la distinta participación nacional de las ventajas del mercado común en formación, corresponde a los productores guatemaltecos la mayor tasa de beneficio, aunque salvadoreños y costarricenses tienen las mayores posibilidades a largo plazo, especialmente para los últimos, cuya sociedad cuenta con una distribución más equitativa del ingreso y mayor poder de compra, más mano de obra calificada, mejores sistemas de comunicación $y$ comercialización $y$ la mayor estabilidad politica de la regiön ${ }^{2}$.

\section{INDICADORES Y'ACHAQUES DEL GREGIMIENTO ÉCONÓMICO}

Entre 1945 y 1965 el sistema económico ha pasado por tres etapas que pueden caracterizarse sumariamente asi:

1. Un periodo que termina aproximadamente en 1955 , durante el cual predominaron en el mercado nacional factores dinámicos de exclusivo origen externo (por ejemplo, altos precios para los productos agricolas como el café) y que fueron aprovechados de manera desigual por los cinco paises de la región según la mayor o menor rigidez de

${ }^{2}$ A. Segal, "La integración cconómica centroumericana", Comercio Exilerior, marzo, 1966. 
su estructura social o en función de los cambios políticos que alteraron también en grado diverso, la dominación oligárquica precedente;

2. Sobreviene luego un periodo, de más o menos un lustro, que termina en los inicios de la década del 60 en el que el ritmo de crecimiento sufre diversos contratiempos que, en esencia, reeditan los sintomas de debilidad de una cconomia dependiente casi con cxclusividad de su comercio de exportación, y

3. Finalmente, un lapso que comprende los últimos 6 ó 7 años, cuando comienzan a aparecer nuevos factores dinámicos en el mercado nacional, pero de naturaleza precaria ya que no han sido superados los factores negativos que desde el exterior influyen tan decisivamente en el comportamiento del sistema económico. En esta etapa se institucionalizan definitivamente los mecanismos del mercado común.

Según los datos del cuadiro I, el crecimiento del Producto Interno Bruto ha sido desigual en distintos años y para los diversos paises. Centroamérica recupera sus antiguos niveles de crecimiento, existentes en los años finales de la década del 20, hasta en los momentos de la postguerra $y$, por lo tanto, los llamados años de auge a partir de 1945 son apenas el restablecimiento funcional del sistema económico tan ampliamente afectado por la crisis mundial y agravado por el comportamiento conservador de la politica anticíclica que se aplicó.

\section{CUADRO I}

IADICES DEL CRECMIENTO DEL PRODUCTO INTER NO BRUTO DE CENTKOAMERICA

\begin{tabular}{lllll}
\hline Paises & 1950 & 1955 & 1960 & 1965 \\
\hline Guatemala & 100 & 126 & 158 & 221 \\
Honduras & 100 & 137 & 166 & 235 \\
Nicaragua & 100 & 158 & 176 & 272 \\
Costa Rica & 100 & 157 & 208 & 302 \\
EiSalvador & 100 & $118^{*}$ & $121^{* *}$ & $192^{* * *}$ \\
\hline
\end{tabular}

- Corresponite al año I95t.

* Corresponde al ar̃a 1958.

* Corrosponde al aĩo 1963 .

FLENTE: Censos nacionales.

En el cuadro de esta situación general que reproduce la persistencia del llamado modelo de crecimiento inducido desde afuera, $y$ en el 
Edelberto Torres-Rivas / Desarrollo, integracionn y dependencia en Centroamérica clima de entusiasmo policlasista por el desarrollo nacional, la politica integracionista pasó a identificarse con la industrialización, convirtiéndose ésta en el simbolo de la mejor política económica. Planteada en su forma tradicional, la política industrial se apoyó en una sobreprotección estatal $y$ buscó realizar los tres objetivos clásicos ya conocidos: dar empleo a una oferta de mano de obra que crece rápidamente; elevar la renta nacional per capita y en general, el nivel de vida de la población, $y$ disminuir la vulnerabilidad externa provocada por la participación en el mercado mundial con productos primarios y mejorar así la situación de la balanza de pagos.

Examinemos rápidamente tales efectos en el análisis del proceso llamado de sustitución de imporlaciones, utilizado ya por otros paises latinoamericanos.

El proceso de industrialización en este modelo de crecimiento sólo tuvo en cuenta la magnitud geográfica $y$ poblacional del mercado $y$ no su profundidad ni su tasä de crecimiento. El fortalecimicnto del mercado interno se quiso resolver por su ampliación horizontal, es decir, la suma de los cinco diminutos mercados locales; de esa manera, aquel mecanismo de adición no facilita sino simplemente posterga la solución de los problemas preexistentes. Es conocida la tasa de crecimiento demográfico de la población centroamericana, una de las más altas del mundo ( $3,3 \%$ anual en 1966$)$; el sector industrial, a pesar de su crecimiento, no es capaz de absorber aquella fuerza de trabajo en . constante expansión y ni aun el conjunto de la economía podria lograrlo sin modificarse internamente. Entre 1950 y I 963 , la oferta de trabajo creció a una tasa anual del $2,4 \%$ y solamente un $80 \%$ del total de la fucrza de trabajo encontró ocupación.

En Costa Rica el sector manufacturero absorbió hasta 1966 un promedio de 1.000 nuevos empleos $y$ se marginaron 1.800 personas anualmente, a pesar que la tasa de crecimiento de tal sector ha sido relativamente alta ( $7 \%$ para el crecimiento industrial $y 3,7 \%$ de crecimiento demográfico). Entre $95^{\circ}$ y I $^{62}$ la industria dio trabajo solamente al $10 \%$ del total de la nueva fuerza de trabajo. En Honduras, la desocupación urbana subió al $6,1 \%$ en $\mathrm{I} 6_{4}$ en Guatemala, la ocupación industrial creció apenas en un $\mathrm{I}, 5 \%$ anual, mientras la población urbana la hacia a 5,1\%. Entre $195^{\circ}$ y 1962 , de las 645.000 personas potencialmente 
E S T U D I O S I N T E R N A C I O N A L E S

incorporadas como población activa, encontraron trabajo efectivo 94.000, lo que significa que una de cada siete personas encontró trabajo en la ciudad y una de cada tres, en el campo. En los últimos cuatro años, de una oferta que sumó 8ז.000 personas sólo 1.500 encontraron colocación fabril. En general, el número de personas absorbidas por este sector casi no aumenta en términos relativos; en 1950, el sector manufacturero ocupaba un $10,8 \%$ del total de la ocupación centroamericana y en 1965 apenas alcanzó el $:$ I, $4 \%$.

Por las circunstancias internacionales en que se produce la dinámica de la sustitución de importaciones, toda la inversión industrial busca la utilización de una tecnologia de labour saving cada vez mayor.

El funcionamiento de las empresas industriales, dada la dimensión del mercado, no alcanza su pleno rendimiento; el círculo vicioso en una sociedad que pretende industrializarse en base a impulsos exógenos $y$ decisiones aisladas de poder, se presenta casi como insalvable: la manufactura no puede absorber la oferta de mano de obra y produce desocupación estructural; como consecuencia, el mercado' consumidor se restringe $y$ las instalaciones fabriles funcionan a un ritmo menor. Suben los costos y disminuye la productividad y ello refuerza el ciclo que dificulta la viabilidad del proceso.

Actualmente la producción supera ya al consumo en numerosos renglones; la ruptura de tal equilibrio acentúa las dificultades insinuadas anteriormente. Las fábricas de alimentos, por ejemplo, trabajan hoy dia a! $50 \%$ de su capacidad, las de plásticos a un $33 \%$ y las de materiales de construcción a un $28 \%{ }^{3}$. Los productos de alambre (alambre espigado, clavos, remaches, etc.) alcanzaron un nivel de 42.000 toneladas en $1965 \mathrm{y}$ la demanda en I'669 apenas será de 35.000 toneladas. Lọ artículos eléctricos (radios, televisores, ampolletas, exclusivamente armados en base a la importación de piezas prefabricadas) duplicaron la demanda entre I953-64 y la producción se triplicó; un informe reciente sobre estos problemas indica que en las ramas intermedias, entre 1953 y 1964 , la producción industrial se elevó en $127 \%$ y la demanda en un $88 \%$ y en la de

${ }^{3} \mathrm{~J}$. Almeida, "La política de industrialización del "mercado comün centroamericano", Revista Brasileira de Economia, Año xx̣1, $\mathrm{N}^{\circ} 1$, marzo, :968. 
Edelberto Torres-Rivas / Desarrollo, integración y' dependencia en Centroamérica minerales no metálicos, la demanda creció en un $41 \%$ y la producción centroamericana aumentó en un $73 \%$.

De ahi que el otro elemento critico, ya señalado, se refiere a que el consumo industrial sólo corresponde a los niveles más altos del ingreso promedio per capita, vale decir, a un mercado comprador ubicado en las ciudades capitales de los cinco paises $y$ en algunas otras concentraciones urbanas dislocadas, en el interior; en conjunto, los cinco mercados nacionales conforman, en una visión optimista, un mercado aproximado de 3 millones de personas. (Ver cuadro número "I de Ingreso per capila).

Un organismo asesor del mercado común calculó que en $: 963$ se habia acumulado ya una capacidad ociosa en el sector fabril equivalente a los i50 millones de dólares (de producto bruto); el bajo poder de compra de la población no ha aumentado en extensión ni en profundidad. Todo parece indicar que ha sido excluido el $75 \%$ de la población (que recibe el $25 \%$ del P.I.B.) que habita en las zonas rurales y en las zonas socialmente marginadas del mundo urbano. Que las clases asalariadas paguen el precio del crecimiento parece corresponder a la naturalcza misma de las relaciones sociales que el establishment supone; los grupos dominantes nacionales $y$ los intereses extranjeros parecen conformarse con la existencia de minúsculos polos de modernización y un estrecho mercado comprador; su estrategia politico-social no pasa por la necesidad de crear mecanismos que hagan posible la ampliación del mercado, la incorporación activa en la estructura del mismo de casi 9 millones de personas ahora excluidas, que no tienen ninguna posibilidad de defensa y representación de sus intereses sociales.

El problema de la absorción de mano de obra por parte del sector industrial posiblemente no podria resolverse ni aun completando, de manera integral, el funcionamiento del mercado común, si previamentc no se ha resuelto el problema social básico que radica en la modificación sustancial de las relaciones socialcs imperantes en el sector rural, que se han constituido en el talón de Aquiles de todo el sistema. La existencia del latifundio improductivo, o del minifundio que lo complementa, dificulta la ampliación de la capacidad de compra de la pobla-

4"Centroamérica: análisis dẹl sector externo f de su relación con el desarrolís económico", :xstrturo, Santiago de Chilc, 1967 , capitulo $m$. 


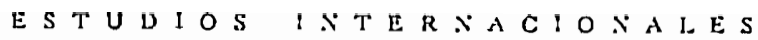

ción $y$ pospone además lá modernización de la agricultura, eje indisculido de todo el cambio social.

CUADRO "

INGRESO NAC:ONAL PEK CAUtTA

(en pesos centroamericanos)

\begin{tabular}{cccccc}
\hline & Gualemnla & El Salvador & Honduras & Niearagua & Costa Rica \\
\hline 1950 & 206 & $*$ & 131 & $*$ & 214 \\
1955 & 218 & $*$ & 173 & $*$ & 279 \\
1960 & 236 & 171 & 182 & $*$ & 300 \\
1965 & 286 & 236 & 194 & $*$ & 352 \\
\hline
\end{tabular}

- No hay información.

FLwite: Quinto compendio estadirtico centroamericano, slics, septiembre, $1967 . \mathrm{g}$. kg.

Entre 1950 y 1964 prosiguió la concentración-ạtomización de la tierra. El Salvador, por ejemplo, con una alta densidad demográfica ( $4_{4} 2$ habitantes por kilómetro cuadrado) alcanzó la llamada fronlcra económica en 1965, y prácticamente no quedan tierras disponibles para asentar la nueva población rural, salvo que se realicen costosas obras de infraestructura; en Honduras y Nicaragua, en cambio, es agudo el desequilibrio ecológico-demográfico dada la superpoblación rural en la pequeña franja del Pacífico y el abandono $y$ desarticulación económica de las cxtensas tierras del Atlántico; de ahi que uno de los mayores problemas para el crecimiento industrial sea la dispersión de la población rural centroamericana. En Honduras sólo el $15 \%$ de la tierra de buena calidad cs utilizada; y más del $35 \%$ de las áreas bajo cu!tivo, en 1963 , se identificaron como agricultura de subsistencia, comprendiendo al $56 \%$ de la población rural, encerrada así en una cconomia casi naturals. La desocupación, que deberia afectar en mayor medida a estas socicdades, no crea los probicmas conocidos en países más desarrollados porque aún se producc al margen de la economía de mercado y sólo determina, como efecto, una baja productividad por persona. En Nicaragua se encuentra en explotación actualmente sólo un tercio de la tierra disponible y 845 latifundios, en su mayor parte pertenecientes a 28 familias, controlan

shonduras, Evaluación del plan para el desarrollo económico y' social 1965-1969. Comité de los nueve, Alianza para el Progreso, Washington, : 966. 
Edelberto Torres-Rivas / Desarrollo, integración y dependencia en Centroamćrica el $4_{2}^{2 \%}$ de la tierra total cultivable. La concentración monopólica, y el minifundio sin embargo, son más agudos en Guatemala; según el censo agropecuario de 1950, habia en el pais 265.629 parcelas menores de 3,4 hectáreas (5 manzanas), con un promedio de $:, 2$ hectáreas por parcela; cálculos hechos por el Instituto Indigenista Guatemalteco indican que el minimo de subsistencia para una familia de 5 personas es de 2,0 hectáreas.

El bajo poder adquisitivo de la población generalmente se esconde detrás del dato estadístico que presenta promedios nacionales, ocultando así una brutal asimetria. Por el clima politico en que se desenvuelve el crecimiento económico centroamericano, se facilita la pcrmanencia de una estructura distributiva del ingreso fuertemente regresiva. La concentración de las rentas en manos de los grupos de la burguesia agraria e industrial y la aplicación particular del ahorro nacional asi formado podria considerarse una condición sine qua non de! desarrollo clásico del capitalismo original; pero el sector privado en Centroamérica se va constituyendo en un ambiente histórico distinto, donde se cruzan estimulos negativos de diverso origen (efecto de demostración en el consu'mo, tasas de ganancia mayores en los mercados del exterior, temor al conflicto antioligárquico, etc.) que limitan el impulso empresarial de tipo schumpeteriano y cercenan la ascesis capitalista que Weber encontró en los origenes de la revolución industrial. De ahi que las rentas generadas en el sector exportador $y$ las que provienen de otros rubros productivos no constituyan un flujo mónetario que se reinvierta de manera ciclica en la expansión continua de las relaciones productivas. Por el contrario, una cuota de la ganancia cafetalera queda normalmente en el exterior; entre 1945 y 1962 y conforme datos oficiales ${ }^{6}$ la burguesía centroamericana tenia, solamente como dépósitos bancarios en el exterior, la suma de 157,6 millones de dólares; este grupo social ha sido, tradicionalmente, exportador de capital, de ahi que resulta dificil calcular ahora el monto exacto de sus operaciones bursátiles y sus inversiones en los mercados del exterior. Y por el otro lado, el consumo suntuario inspirado por los niveles de vida de las clases altas de las sociedades más desarrolladas, así como lá preocupación por el uso de

${ }^{6}$ Naciones Unidas, El financiamiento externo de América Latina, Nueva York, 1964 , cuadro $N^{\circ} 7^{8}$. 
E S TUDIOS I N T E R N A C I O N A L E S

simbolos de prestigio social que los diferencie de la masa, lleva a las "aristocracias" locales a dilapidar parte del ahorro que pasa por sus manos; los costosos barrios elegantes de las metrópolis centroamericanas son apenas un testimonio de aquel comportamiento.

La politica de sustitución de importaciones se realiza en el caso centroamericano cuando las condiciones del comercio internacional son cualitativamente distintas de las que predominan en la década del 30, caracterizadas por una crisis general del sistema capitálista mundial; la sustitución forzosa de importaciones, en la época actual, se produce de manera simultánea con la reordenación del comercio y del sistema internacional, que en la postguerra desarrolla nuevos rasgos monopólicos y nuevas formas de expansión; actualmente, la crisis del comercio exterior no ha desaparecido sino que adopta nuevas dimepsiones para los paises de la periferia. La etapa de llamado desarrollo hacia adentro que el Mercado Común intenta dinamizar coincide con esta expansión industrial-financiera del sistema capitalista en generàl y de mercado norteamericano en particular, asi como con alteraciones en las relaciones comerciales y politicas con el resto del mundo. (Véase cuadro $\mathrm{nI}$, donde se demuestran las cuantiosas pérdidas en el comercio internacional). ¿En tales condiciones, coincide el fortalecimiento del mercado nacional, teóricamente presentado como garantía del éxito del proceso de industrialización con los propósitos de inversión y lucro del capital internacional? ¿Hay penetración externa en el mercado local, o quizás éste sólo puede constituirse a partir de esa penetración? ¿Se han agotado prácticamente las posibilidades del crecimiento inducido desde afuera cuando el café y el algodón contribuyen aún sustancialmente en Centroamérica a la formación del producto nacional?

El proceso actual continúa desarrollándose en el molde anacrónico del comercio internacional originado el siglo pasado, y la vulnerabilidad económica no disminuye sino que, por el contrario, se acrecienta como una deuda externa que termina por desequilibrar, a largo plazo, la balanza de pagos. La tendencia decreciente en los precios de los productos primarios no ha podido ser compensada con aumentos sustanciales en el volumen de ventas y la brecha del comercio exterior, caracterizada por una insuficiencia en aumento de los medios internacionales de pago, ha pasado de los rgo millones en 1965; a 
Edelberto Turres-Rivas / Desarrollo, integración g dependencia en Centroamérica CUADRO 11

DETERIORO EN LOS TERMMNOS DEL INTERCAMBIO COMEKCIAL EN

CENTROANERICA

imillones de dólares de 1953)

\begin{tabular}{|c|c|c|c|c|c|c|}
\hline ATror & Guatemala & El Saluador & Ilondtiras & .liearagua & Cossa Rica & Tatal \\
\hline 1950 & $-10,5$ & 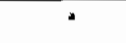 & $-8,2$ & $-10,5$ & 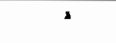 & $-29,2$ \\
\hline 1951 & $-\quad 4,8$ & $\cdot$ & $-5,6$ & $+\quad 0,9$ & s & $-\quad 9,5$ \\
\hline 1952 & $-\quad 2,5$ & 2 & $+3,3$ & $-\quad 0,9$ & $-6,4$ & $-6,5$ \\
\hline $1953 \mathrm{~b}$ & 0 & 0 & 0 & 0 & 0 & - \\
\hline 1954 & $+8,4$ & $+28,8$ & $+1,6$ & $+16,9$ & $+2,9$ & $+58,6$ \\
\hline [95, & $+6,6$ & $+7,7$ & $+5,9$ & $+12,8$ & $-5,2$ & $+27,8$ \\
\hline$: 956$ & $+7,4$ & $+13,9$ & $+16,6$ & $+3,6$ & $+2,1$ & $+43,6$ \\
\hline$\lfloor 957$ & $+6,7$ & $+9,1$ & $+6,8$ & $-12,8$ & $-3,7$ & $+6,1$ \\
\hline 1958 & $-16,3$ & $-18,0$ & +4.4 & $-15,8$ & $-20,4$ & $-66,1$ \\
\hline 1959 & $-32,1$ & $-36,7$ & $-2,8$ & $-25,8$ & $-27,5$ & $-124,9$ \\
\hline 1960 & $-48,6$ & $-27,6$ & $-8,9$ & $-20,1$ & $-35,4$ & $-140,6$ \\
\hline 1961 & $-61,2$ & $-40,3$ & $-6,1$ & $-14,1$ & $-41,7$ & $-163,4$ \\
\hline 1962 & $-63,2$ & $-51,5$ & $-6,0$ & $-33,7$ & $-47,0$ & $-201,4$ \\
\hline 1963 & $-113,8$ & $-60,7$ & $-1,2$ & $-13,2$ & $-42,1$ & $-231,0$ \\
\hline 1964 & $-78,0$ & $-58,9$ & $+3,6$ & $-\quad 5,1$ & $-32,2$ & $-1.70,6$ \\
\hline 1965 & $-89,5$ & $-45,4$ & $+1,7$ & $-4,3$ & $-33,2$ & $-170,7$ \\
\hline 1966 & $-118,1$ & $-42,2$ & $-10,1$ & $-9,0$ & $-41,6$ & $-221,0$ \\
\hline 1967 & - & - & - & - & - & - \\
\hline 'l'otal & $-609,5$ & $-321,8$ & $-5,0$ & $-131,1$ & $-331,4$ & $-1.398,8$ \\
\hline
\end{tabular}

No hay daio.

b Jĩo utilizado comn deflactor del indice.

FCE: $\backslash$ : Estadisticas nacionales del comercio exleriver, cuadro prepando por el autor.

208 en r 966 y 284 millones de dólares de déficit en 1967 . En tal periodo cl aumento de las exportaciones ha sido mínimo $(1,1 \%)$ y las importaciones aumentaron en $10,2 \%$. La solución transitoria, dada la situación de poder interno, ha sido el endeudamiento externo, a través de la financiación del déficit con empréstitos e inversión externa. Las inversiones directas netas de órigen externo entre 1950-:967 suman 614 millones de dólares, correspondiendo la cuota mayor a Guatcmala ( 177 millones) y a Honduras ( $15^{2}$ millones) ${ }^{7}$, micntras que la deuda pública externa subió de los 120 millones de dólares (1950) a 375

7 Para los otros paises las cantidades son: Costa Rica 111,8 , Nicaragua $9 !, 4$ y El Salvador (4),7 millones. 
ESTUDIOS INTERNAC:ONALES

(ig64) y a 430 (:g66). Habia que mencionar que gracias a los contratos suscritos antaño entre las compañias bananeras, $y$ luego al amparo de los Convenios de Garantia a las Inversiones norteamericanas los págos por servicio de capital extranjero a largo plazo (utilidades, intercses $y^{\prime}$ amortizaciones) asciende (entre I950-ig63) a 354,2 millones de dólares.

\section{¿A DÓNDE VA CENTROAMLRICA?}

Los mecanismos de la industrialización experimentados ya por otras sociedades periféricas, han empezado a producir resultados similares en la región. Se trata de los mismos fenómenos de desocupación estructural, crecimiento urbano desordenado $y^{\prime}$ anormal, $y$ creciente marginalización de importantes sectores sociales. Asi, por via indirecta, el crecimiento industria! resuelve aigunos problemas pero condiciona el surgimiento de nuevas situaciones de conflicto social que no pueden ser resueltas cn la'medida que el funcionamiento general de la sociedad se torna más y más dependiente.

Es sabido que los paises del Mercado Común Centroamericano, como los del resto de América Latina son constitutivamente dependientes; o sea, que se organizan como Estados nacionales, el siglo pasado, proceso que es consecuencia del establecimiento de vinculos cconómicos y' políticos de ta! naturaleza, dentro de la estructura del mercado capitalista mundial, que determinan una manera propia, interna de organización. Dejaron de ser una colonia peninsular para constituirse paradójicamesite, en Estados nacionales pero dependientes. La incorporación de la socicdad latinoamericana (roto el vínculo colonial con España y' Portugal) como complemento de las economias centrales en la etapa expansiva del capitalismo mercantil financiero creó las condiciones para la formación de nuestra nacionalidad.

Con las más recientes tendencias a la inversión de capital extranjero, dirigidas al sector manufacturero industrial, empieza a configurarse ya una nueva situación en la relación de dependencia que, desde el momento mismo de su constitución, afecta a las naciones centroame-

6 "Cenlromérical análisis del sector externo", cit., p. vi-1g. 
Edelberto 7orres-Rivas / Desarrollo, integración y dependencia en Centroamérica ricanas. Se trata de un momento cualitalivamente distinto de los anteriores, porque apoyándose $y$ a partir de ellos, aparecen nuevas formas de interdependencia entre la sociedad periférica en su conjunto y' el mercado capitalista mundial donde ahorn predominan los grandes consorcios industrial-financieros. Pero como sc trata de una región de formación agraria, la interdependencia que se expresa en un vínculo comercial -oferta de productos primarios casi con carácter de monoexportación - se ve ahora complementada con los lazos sin cuyo establecimiento no es posible intentar la diversificación del sistema económico a través del "modelo" de desarrollo industrial; estos intentos se inscriben en una situación histórica en que las posibilidades de gencrar una tecnologia propia son incxistentes; la necesidad y la posibilidad del crecimiento industria! nacional corresponden en esta época a una nueva forma en la expansion del capitalismo, por la cual se redefinen en las áreas periféricas la pretérita división internacional del trabajo y pasan a ser estas áreas un mercado de inversión y de complementación industrial indispensables para la cconomía de la metrópoli. Es decir, la industrialización sólo es posible en el marco de este mercado, como complementación industrial, $y^{\prime}$ por lo tanto la industrialización nacional como industrialización subordinada; la "sucursalización" con respecto a una gran empresa matriz exterior cs posible por la capacidad tecnológica y de inversión que ésta detenta y porque debico a esa capacidad necesita constante $c$ irrecusablemente extenderse cada dia a nuevas áreas de inversión. En la interdependencia asi establecida, los contenidos de la relación de dependencia no son sôlo las inversiones industriales striclu sensu y la consiguiente repatriación de utilidades a la metrópoli, sino la dependencia tecnolögica, la capitalización a través de recursos financieros foráneos, el cndeudamiento externo, la desnacionalización de la banca nacional $y$, en general, la conformación de una estructura social y politica interna que se adapta y funciona para hacer posible la realización nacional de los intereses extranjeros.

Al analizar el cambio social destaca finalmente el papel del Estado, sin cuya activa presencia los actores sociales que participan, se relacionan y se enfrentan en el mercado, no hubiesen sido capaces de enfrentar las tareas planteadas en el proceso de transformación; sólo a través de la gestión estatal cobran sentido los intereses y las relaciones 
de los grupos sociales y especialmente en los momentos cn que la interacción social se encuentra en un punto de viraje.

El Estado, que pretende alzarse como la representación de todas las fuerzas sociales de la sociedad civil, sè encuentra sujeto por condiciones de un doble carácter que en esta coyuntura le dan al desarrollo general rasgos contradictorios. Por una parte, hace crisis el propósito de representatividad $y$ consenso que el Estado normalmente reclama, como consecuencia del debilitamiento de la base social del poder politico originado en la paulatina exciusión de importantes estratos sociales; la inestabilidad institucional aparece como rasgo común del sistema politico, tal vez con la excepción de Costa Rica; y esta situación ha conducido, en más de una oportunidad, a cuestionar la legitimidad del orden total. Esta situación, que podria inscribirse en el marco general de la crisis de la dominación oligárquico-tradicional, se caracteriza en muchos momentos por la utilización de la violencia física como expresión última de aquella dominación, y en último término, por una pérdida de dinamismo en el proceso de domocratización del sistema. Por otra parte, un debilitamiento orgánico, a pesar de las nuevas funciones que realiza el Estado, ya que el sector público cede cada vez más al scctor privado las oportunidades de encabezar algunas actividades que podrian, seguramente, fortalecer su gestión dirigente.

Dos son las preguntas claves en el futuro del sistema politico; ¿corresponde la inestabilidad politica en Centroamérica, a la búsqueda de una nueva legitimidad del poder donde pueda lograrse exclusión y consenso popular al mismo tiempo? ¿Cómo puede llegarse a un nuevo equilibrio para establecer un Estado politico socialmente fuertc. capaz de impulsar las decisiones de desarrollo $y$, al mismo tiempo, mantener su control por los mismos sectores sociales que hoy lo dirigen?

Las exigencias implicitas en el ćrecimiento económico, en los últimos años, han determinado una ampliaciór relativa de la actividad pública en aspectos no tradicionales de su actividad. El aumento de las funciones estatales encuentra, sin embargo, algunos obstáculos; el sector público no cstaba preparado para descmpeñar un papel decisivo en el proceso de desarrollo, ni para impulsar concretamente en el plano nacional las reformas que la integración económica neccsita. Pero además, los grupos propietarios, hoy día influyentes, son parti- 
Edelberto Torres-Rivas / Desarrollo, integración y dependencia en Centroamirica darios de dejar en libertad a las fuerzas del mercado, reduciendo así el papel que le corresponderia desempeñar al Estado. La politica integracionista, por una parte, requiere un tipo de actividad dinámica por la cual el Estado debcria convertirse en centro planificador, impulsor y ejecutor de muchas tareas básicas, pero por la otra, se rechaza la planificación y' la intervención de aquél.

A partir de la medida preliminar de liberación del comercio intercentroamericano, por ejemplo, los partidarios de dejar en "libertad" a las fuerzas del mercado impulsan una politica que ascgure la libre empresa, sin ninguna interferencia, pero en un clima de sobreprotección cstatal. Es decir, "libre" empresa, pero no en siluación de libre competencia, sino bajo la decidida tutela del Estado para asegurarse formas acusadamente monopólicas de producción y distribución. El sector püblico funciona de esa mancra como un simple implementador, no sicmpre eficaz, de las necesidades del sector privado, en circunstancias que la participación del Estado es imprescindible, en unos casos por la magnitud de las inversiones a rcalizar y en otros por obstáculos sociopoliticos por remover.

Desde un punto de vista más bien programálico, frecuentemente se postuló que al superar las líneas tradicionales de participación en cl mercado mundial (lo que implica una transformación radical en el modelo monoexportador agricola) y al tener éxiso una politica de fortalecimiento del mercado interno (lo que supone una reorganización del mundo rural y una redistribución radical del ingreso) surgirian condiciones para la consolidación del Estado nacional centroamericano; en esta perspectiva, abandonar el marco de las cinco pequeñas naciones para recuperar la dimensión política e histórica de la vicja República Federal podria considerarsc como el intento viable de autonomia a que puede aspirar una área perilérica. Pero la integración politica, por el momento, sólo constituye un objetivo a largo plazo.

Finalmente, resumamos las ideas precedentes: si, como consccuencia de las fuerzas sociales $y$ politicas que dirigen hoy dia la sociedad centroamericana, no hay desarrollo social, ni menor dependencia del centro hegemónico, ni tampoco efectiva demócratización politica, ¿para qué, cntonces, la integración centroamericana? 